for her helpful criticism and advice during the preparation of this paper.

\title{
REFERENCES
}

1. Collins, E. T. (1897).-Trans. Ophthal. Soc. U.K., Vol. XVII, p. 254.

2. CRUise, R. R. (1905).-Trans. Ophthal. Soc. U.K., Vol. XXV, p. 332.

3. Gregg, N. MCA. (1941).-Trans. Ophthal. Soc. Australia, Vol. III, p. 35.

4. MANN, IDA (1937).-Developmental Abnormalities of the Eye. Cambridge University Press, London. Fp. 16 and 98.

5. Mayou, M. S. (1904):-Trans. Ophthal. Soc. U.K., Vol. XXIV, p. 340.

6. Mayou, M. S. (1908).-Trans. Ophthal. Soc.U.K., Vol. XXVIII, p. 107.

7. Swan, C., Tostevin, A, L., Moore, B., Mayou, H. and Black, G. H. B. (1943).-Med. Jl. Australia, Vol. II, p. 201.

8. Swan, C. (1944).-Jl. Path. and Bact., Vol. LVI, p. 289.

9. Terry, T. L. (1945).-Jl. Amer. Med. Assoc., Vol. CXXVIII, p. 582.

\section{ADHESIVE EPISCLERAL REACTION IN THE OPERATIVE TREATMENT OF RETINAL DETACHMENT*}

BY

\author{
L. WEEKERS \\ LIEGE
}

THE various procedures used in the operative treatment of detachment of the retina aim at causing adhesive choroiditis at a spot corresponding exactly to the place of the tear : the tear is to be engulfed by the area of the operative chorioretinitis and thus indirectly obliterated.

We believe that in addition to the choroiditis, one should endeavour to promote an adhesive episcleral reaction, as this contributes greatly to the immediate operative result and helps to preclude relapses.

\section{1.-Experimental observations}

We would first briefly recall certain experimental observations which we published previously: 123

Fig. 1 refers to a simple but significant experiment. We used a cataract knife, considerably thinned by wear; the point was sharpened as much as possible so that the blade was but a thin flat needle, extremely sharp. After having instilled a few drops of cocaine, the point of the knife was driven into the eye of a rabbit at a point distant from the limbus, adjoining the superior rectus,

\footnotetext{
* Received for publication, September 12, 1946.
} 


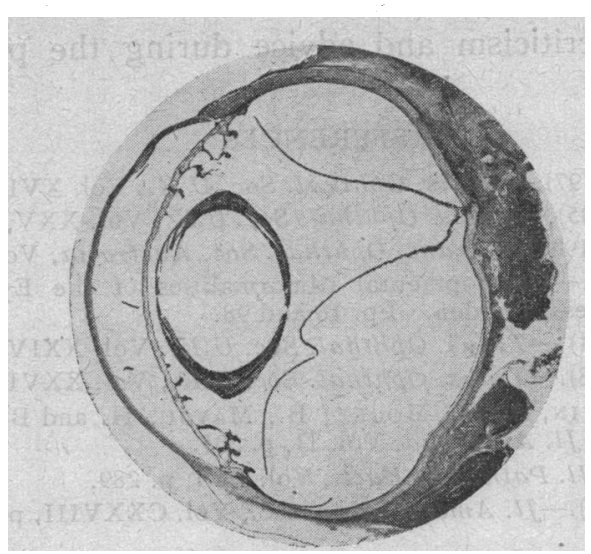

FIG. 1.

An experimental episcleral adhesion (rabbit).

the muscle itself being seized by forceps to fix the globe. The knife penetrated through all the layers : conjunctiva, episclera, sclera, choroid, and retina, but is driven only just far enough for the perforation to be complete.

Immediately afterwards, the place of the perforation can readily be observed with an ophthalmoscope; it shows as a small white spot; sometimes a slight haemorrhage may be noticed. Later, there is discrete pigmentary reaction.

After a variable length of time, the eye is enucleated and put into preservative fluids (fixing agents and alcohols). In the normal rabbit eye so treated, the retina becomes detached. When, however, a preliminary scleral perforation is performed, even though only a short time before ( 3 or 4 days), the retina, detached everywhere else, remains attached at the point of perforation (Fig. 1).

Where several perforations are performed, a few millimetres apart, the retina remains adherent at each spot. Fig. 2 shows four such adhesions.

Histological examination shows the mechanism of these adhesions. The scleral gap resulting from the perforation heals with the aid of the episcleral tissue. This proliferates, penetrates into the wound, develops in depth, and reaches the retina. The newly formed episcleral tissue and the retina become firmly adherent. For the section shown in Fig. 3 enucleation was carried out six weeks after experimental perforation. As a result of the retraction of the tissues, the episcleral tissue is artificially detached from the sclera, but the firmer adhesion to the retina remained intact.

To test whether the episcleral reaction noted in rabbits also takes place in the human eye with its substantially thicker sclera, human 
eyes were perforated at various times before enucleation necessitated by different diseases. It was found that in the human eye too, even when the scleral gap is very narrow, the proliferating episcleral tissue reaches the retina within a few. days.

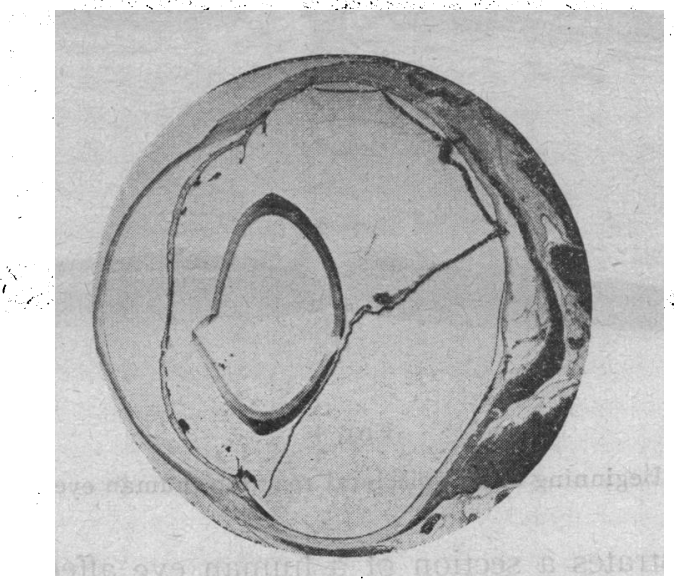

Fig. 2.

Four experimental episcleral adhesions (rabbit).

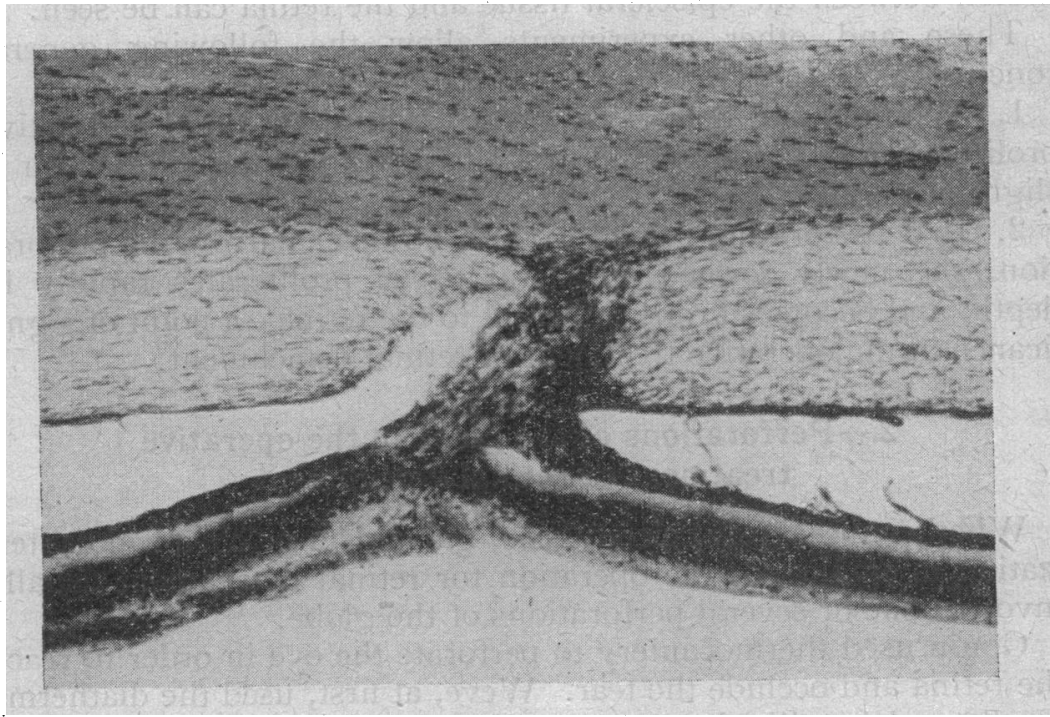

FIG. 3.

Adhesive episcleral reaction (rabbit). 


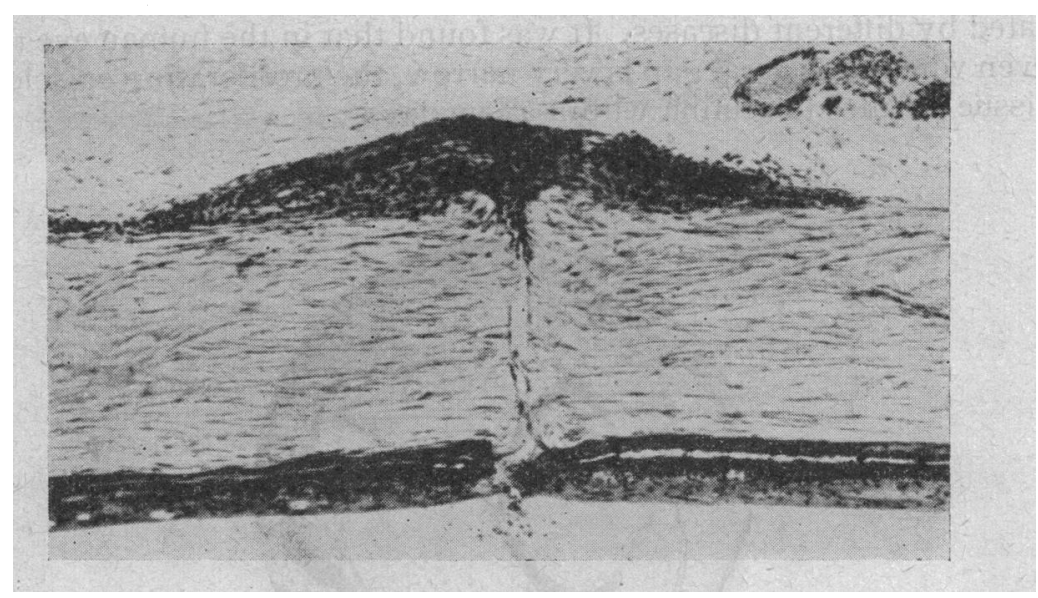

FIG. 4.

Beginning of an episcleral reaction (human eye).

Fig. 4 illustrates a section of a human eye affected by painful absolute glaucoma. Five days before enucleation the eye was perforated as in the experimental animal. Histologically, considerable proliferation of the episcleral tissue is seen, extending into the scleral gap which is still mainly empty. After about 8 days adhesion between the episcleral tissue and the retina can be seen.

These and other experiments allow the following general conclusions :

1. Wounds and defects of the sclera heal by rapid and active proliferation of the episcleral tissue. Healing in the sclera itselt is slight or negligible.

2 . In a perforating scleral wound, however narrow the perforation, the newly formed episcleral tissue proliferates rapidly in depth, and becomes firmly adherent to the retina-a point of significance in the operative treatment of retinal detachment.

\section{2.-Perforations of the globe in the operative treatment of retinal detachment}

Whether diathermy, electrolysis, galvanism or chemical cauterization is employed, the operation for retinal detachment usually involves one or several perforations of the globe.

Gonin used thermocautery to perforate the eye in order to reach the retina and occlude the tear. Weve, at first, used the diathermy needle and is still of opinion ${ }^{4}$ that, in certain cases, it is advantageous to coagulate the retina directly. In contrast, multiple diathermic microperforations (Weve, Safar) aim at producing an 
adhesive choroiditis. Perforation of the globe in the course of the operation also allows the escape of the sub-retinal fluid, and it is generally agreed that this evacuation should be as complete as possible in order that the detached retina may be better placed to become adherent to the wall of the eye. The value of episcleralretinal attachments that result from perforation are, however, not fully appreciated.

- The adhesion of the retina which is being sought for at the place of the retinal tears and the consequent obliteration of these tears, are the result of two different processes : adhesive choroiditis and episcleral proliferation. Though associated, they are distinct, each affording particular advantages.

Episcleral proliferation gives the retina limited but strong adhesions, highly protective against relapses. Adhesive choroiditis obtained for instance by a superficial diathermic coagulation of the sclera, has a more wide-spread action; a larger retinal surface is reached, but the adhesions thus obtained are not so strong and give less security against relapses.

\section{3.-Technique of operation aiming at adhesive episcleral reaction}

An indispensable condition for obtaining episcleral retinal adhesions is that the eyeball be completely perforated. Only then can the newly formed episcleral tissue originating from the surface reach the retina.

Animal experiments showed that the episcleral reaction occurs whatever the mode of perforation (needle, knife, galvanocautery, diathermy electrode, etc.), but the reaction is the quicker the less the operative trauma.

Experimentally, the procedure which appears most efficacious consisted in simply perforating the eyeball by means of the point of a sharp cataract knife, but it has the drawback that it may cause a haemorrhage.

When a perforation is performed by means of the fine point of a galvanocautery, proliferation of the episcleral tissue towards the retina seems rather slower; it is delayed by the presence of necrotic tissue in the wound.

In the course of an operation for detachment there is a distinct advantage to perform several perforations so as to increase the number of episcleral adhesions. Therefore it is necessary to avoid escape of sub-retinal fluid after the first perforation, for this would soften the globe and make subsequent perforations more difficult and risky.

The following procedure is simple and satisfactory : 
An ordinary angled and insulated diathermy needle (length : $2 \mathrm{~mm}$., diameter : $0.15 \mathrm{~mm}$.) is used. The diathermy apparatus was previously gauged on an eye to be enucleated; thus it was possible to determine beforehand the weakest current required for an easy penetration by the needle. The knob of our apparatus (Sanitas Ophthalmotherm) is turned to division 2. The point of the needle is placed against the sclera. Slight pressure applied as soon as the current is on causes instantaneous perforation. The needle is then swiftly withdrawn without turning off the current. The whole manoeuvre is carried out in less than a second. Generally, no fluid escapes through the perforation thus performed.

The reason for the electric current being turned on is two-fold : to facilitate perforation and avoid a haemorrhage. The aim of the preliminary gauging is to determine the minimum intensity of the current which ensures the practically instantaneous penetration of the needle into the sclera. Occasionally, when the first perforation is performed the current proves insufficient for an easy penetration of the needle; the intensity is then slightly increased for the subsequent perforations. These perforations leave ophthalmoscopically visible scars after cure : small white spots with a slight pigmentary reaction. They are similar to the scars observed in the experimental animal. According to the area to be covered, the number of perforations varies from three to twenty. It is remarkable that the last perforation can be carried out as easily as the first.

\section{4.-Steps in the operation for retinal detachment incorporating puncture for adhesive episcleral reaction}

1. We first apply the non-perforating diathermic electrode on the sclera in order to promote the indispensable choroidal reaction at a place corresponding to the retinal tear.

2. We then carry our perforation of the globe as described in detail above-not to promote choroiditis (which has already been cbtained by the superficial electrode) but to induce participation of the episclera. The intensity of the current is just sufficient to facilitate the penetration of the needle and to avoid a haemorrhage. The needle is very thin; its penetration and removal last less than a second together; under those conditions there is no escape of sub-retinal fluid and the eyeball does not soften. As many perforations as required can be carried out without difficulty.

By means of the diathermy needle, both the choroidal and episcleral reactions can be induced simultaneously $(e . g$., method of microperforations of Weve and Safar). We believe, however, that, in order to obtain the two reactions with utmost efficiency, it is best to promote them separately, first the choroidal reaction by means of the non-perforating superficial diathermy electrode, then the 
episcleral reaction by means of the perforating diathermy electrode.

3. We conclude the operation by the evacuation of the sub-retinal fluid. This may be achieved by means of a perforating diathermy needle but, in order that the evacuation be thorough, which we consider as greatly desirable, it is necessary to use a needle sufficiently thick and an electric current sufficiently strong; this may be. comparatively dangerous. We prefer to use the galvanocautery in the following manner, which appears to be the least disturbing.

The cautery is heated to a dark red colour. The sclera is then lightly touched at the required spot with the sharply bent point of the cautery, which is immediately withdrawn. Thus a small cup is formed. After an interval of a few seconds, the same manoeuvre is repeated and the cup deepened. With two or three such manipulations the perforation is completed and the fluid escapes. Sometimes, even when the perforation has been completed, the subretinal fluid does not escape, because the opening has been obstructed by some nec rotic tissue. In such cases we insert the blunt end of a lacrymal probe into the opening; when it is withdrawn, the sub-retinal fluid escapes freely. A single perforation is sufficient for the entire evacuation of the fluid.

It may appear exaggerated to study minutely a surgical act so simple as perforation of the eyeball during operations on detachment. This is surely not the case. Operations on detachment call for no special manual skill, yet the results vary considerably with different operators. When choosing a method, it is not sufficient that it ensures cures; it is necessary that the proportion of cures be as high as possible, and with but few relapses. In operations on retinal detachment, perhaps more than in others, success depends on an accumulation of details and on full appreciation of the limitations and effects of the various steps employed.

The use of a simple diathermy needle offers a good illustration. Several factors (length and diameter of the needle, intensity and duration of the current) have to be taken into consideration, which may combine differently and produce entirely different effects. If the needle is very short and non-perforating, adhesive choroiditis may take place, but there will be no adhesive episcleral reaction. According to the way in which the diathermy needle is used, the retina itself will or will not be coagulated. Certain technical conditions enable many perforations without undue trauma; others diminish the risk of haemorrhage. According to the method employed, the evacuation of the sub-retinal fluid will be partial or complete. 
These and such-like technical aspects influence the proportion of cures. Perforation of the eyeball in the course of operation of the retinal detachment deserves special study, and the value of the adhesive episcleral reaction to be more widely known.

\title{
Summary
}

- The various procedures used in the operative treatment of retinal detachment aim at promoting adhesive choroiditis at the retinal tear. Based on experimental and clinical observations, and especially on operative results, the author believes that, apart from adhesive choroiditis, it is necessary to create an adhesive episcleral reaction, the importance of which is paramount, because it affords particularly firm attachments which militate against relapses.

An adhesive episcleral reaction takes place irrespective of the method of perforation provided the perforation is complete. The episcleral tissue proliferates actively, progresses in depth and becomes firmly attached to the retina. The author describes an operative procedure which gives a satisfactory adhesive episcleral reaction.

\section{REFERENCES}

1. WEEKERS, L.-Arch. d'Ophtal., Vol. XXXIX, p. 583. 1922.

2. Arch. d'Ophtal., Vol. LII, p. 636. 1935.

3. Arch. d'Ophtal., Vol. II, p. 193. 1939.

4. Weve, H. J. M.-In Modern Trends in Ophthalmology, ed. F. Ridley and A. Sorsby, London. Butterworth, p. 553. 1940.

\section{SULPHAPYRIDINE-RESISTANT KOCH-WEEKS CONJUNCTIVITIS*}

BY

\author{
H. J. STERN \\ (MAJOR, R.A.M.C.)
}

IN The Lancet of May 26, 1945, I published with B. Miterstein a report on the outstanding results obtained with sulphapyridine by mouth in Koch-Weeks conjunctivitis. Three grammes of sulphapyridine daily in adults and correspondingly less in children, without any local treatment, clears up the conjunctivitis completely in so short a time that the hitherto used treatment with silver nitrate seemed slow and antiquated in comparison.

* Received for publication, July 12, 1946. 